\title{
1-Iodoundecane, an Estrus Indicating Urinary Chemo signal in Bovine (Bos Taurus)
}

\author{
G. Archunan ${ }^{1 *}$ and Ramesh Kumar $K^{2}$ \\ ${ }^{1}$ Centre for Pheromone Technology, Department of Animal Science, Bharathidasan University, Tiruchirappalli - 620 024, Tamilnadu, India \\ ${ }^{2}$ Department of Zoology, Rajah Serfoji Government College, Thanjavur - 613 005, Tamilnadu, India
}

\begin{abstract}
The time of ovulation and co-ordination of sexual behaviour is important for the successful artificial insemination In our previous studies, urine samples were collected from the bovine at pre-pubertal, pro-estrus, estrus, postestrus, pregnant and lactating animals and a number of compounds were identified by Gas chromatographymass spectrometry (GC-MS); 1-iodoundecane and di-n-propyl phthalatepresent in estrus, the bioactivity of these compounds were not tested to confirm the efficacy of their estrus-specific compounds. So, the present study was planned to confirm the nature of these compounds through testing with bull's bioactivity. The bioassay was carried out in three different groups exposed to water (Control), estrus urine and estrus-specific synthetic compounds. The behavioural study revealed that the compound 1 -iodoundecane identified in the estrus urine exhibits more attraction in bull by enhanced flehmen behaviour when compared to di-n-propyl phthalate. This clearly indicates that the 1-iodoundecane in the estrus female urine is an effective estrus-specific chemical signal which may be used as marker to detect estrus in bovine.
\end{abstract}

Keywords: Estrus; Bovine; 1-Iodoundecane; GC-MS; Urine; Chemo signal

\section{Introduction}

Mammalian pheromones are involved in much reproductive behaviour including sexual attraction [1], social behaviours [2], and individual identification [3]. Urine is one of the most primitive as well as major source of mammalian pheromones $[4,5]$. It is apparent that pheromones carry message between animals through air which must be reasonably volatile and chemically stable during diffusion [6]. Studies on mammalian chemo communication on the laboratory species like mice, rats, golden hamsters etc., are available $[7,8]$, but in bovine such studies are scanty and hence, the reproductive potential of cattle is not fully exploited.

In rabbit, as many as 21 volatiles are identified in the milk but the bioassay cleanly showed that the only one volatile, i.e. 2-methylbut-2enal, attracted the rabbit pups and confirmed this volatile as pheromone molecule responsible for young one to get milk from mother [9]. As for the bioassay of identified compounds concerned, there may be several tools to test the compounds. The 'Flehmen' behaviour is one of the best indicators which are exhibited by bull when the female is in estrus. For instance, the estrus-specific volatile compound is confirmed in elephant and bovine through the 'Flehmen' response [10-12].

One of the most important problems in the cattle is the lack of effective estrus detection in large herds of cows [13]. In most of mammalian species except primates the estrous females express the desire and inform the male of their receptive state by means of chemical signals from urine and vaginal discharge [14]. The chemical signals produced from female during specific period initiate male partner to exhibit a variety of copulatory behaviour which end up with coitus. For instance, under field conditions, bulls show various behavioural responses such as sniffing, licking and repeated flehmen response to chemical cues from the urine. In our earlier studies, GC-MS studies revealed that two-estrus specific compounds viz., 1-iodoundecane and di-n-propyl phthalate have been reported [15]. However, the identified compounds need to be confirmed for their pheromonal activity through testing with bull and this could give more information in relation to olfactory communication of bovine urinary compounds. Therefore, the present work was carried out to evaluate the bioactivity of the synthetic compounds of estrus phase through the behavioural observations with bull.

\section{Materials and Methods}

The behavioural assay was performed on the freely behaving bulls under natural conditions. The assay was carried out in $500 \mathrm{~m}^{2}$ pen where mature bulls were housed. Healthy bulls (Bos taurus) were selected for the study. The estrus-specific compounds viz., 1-iodoundecane and di-n-propyl phthalate were procured from Aldrich chemical company, USA. The bioassay was carried out in three different groups i) Control (water), ii) estrus urine iii) estrus-specific synthetic compounds. The samples were placed in a fresh petridish and the bulls were allowed to sniff the samples. The assay was conducted when there was no rain or strong wind in order to reduce the misbehavior of the animals. The behavioural activities of bulls were observed for a period of 15 minutes. Each sample was presented to the bull in a fresh petridish. Responses were scored as neutral (no response) and aversive (positive response). During the assay a sequence of bull behaviours (i.e. attraction, salivation, urination, tongue manipulation, flehmen, vocalization, penis protrusion, mounting and copulation) was assessed in response to estrus urine, synthetic compounds (1-iodoundecane and di-n-propyl phthalate) and the control samples.

*Corresponding author: G. Archunan, Centre for Pheromone Technology,Departmen of Animal Science, Bharathidasan University, Tiruchirappalli - 620 024, India, Tel: 0431-2407040; Fax: 0431-2407045; E-mail: garchu56@yahoo.com

Received April 27, 2012; Accepted September 03, 2012; Published September 05, 2012

Citation: Archunan G, Ramesh Kumar K (2012) 1-lodoundecane, an Estrus Indicating Urinary Chemo signal in Bovine (Bos Taurus). J Vet Sci Technol 3:121 doi:10.4172/2157-7579.1000121

Copyright: (c) 2012 Archunan G, et al. This is an open-access article distributed under the terms of the Creative Commons Attribution License, which permits unrestricted use, distribution, and reproduction in any medium, provided the original author and source are credited. 


\begin{tabular}{|c|c|c|c|c|c|c|c|c|}
\hline \multirow[b]{2}{*}{ Samples } & \multicolumn{8}{|c|}{ Proportion of male behaviours } \\
\hline & Attraction & Sniffing & Salivation & Urination & Tongue Manipulation & Flehmen & Vocalization & Penis Protrusion \\
\hline Control & $0^{\mathrm{a}}$ & $0^{\mathrm{a}}$ & $0^{\mathrm{a}}$ & $0^{\mathrm{a}}$ & $0^{\mathrm{a}}$ & $0^{a}$ & $0^{a}$ & $0^{a}$ \\
\hline Estrus Urine & $4.66 \pm 0.09^{b}$ & $3.83 \pm 0.05^{b}$ & $3.83 \pm 0.05^{b}$ & $3.66 \pm 0.03^{b}$ & $3.16 \pm 0.98^{b}$ & $3.00 \pm 0.07^{b}$ & $2.50 \pm 0.20^{b}$ & $2.6 \pm 0.18^{b}$ \\
\hline 1-iodoundecane & $6.00 \pm 0.00^{c}$ & $5.84 \pm 0.06^{c}$ & $5.50 \pm 0.02^{c}$ & $5.10 \pm 0.20^{c}$ & $5.33 \pm 0.08^{c}$ & $5.1 \pm 0.20^{\circ}$ & $4.16 \pm 0.28^{c}$ & $4.16 \pm 0.20^{\circ}$ \\
\hline di-n-propylphthalate & $1.84 \pm 0.00^{d}$ & $0.66 \pm 0.08^{d}$ & $1.00 \pm 0.00^{\mathrm{d}}$ & $0.83 \pm 0.74^{\mathrm{d}}$ & $0.76 \pm 0.08^{d}$ & $0.65 \pm 0.08^{d}$ & $0.66 \pm 0.08^{d}$ & $0.65 \pm 0.08^{d}$ \\
\hline
\end{tabular}

Table 1: Shows the various behavioral activities of bull towards the estrus specific compounds $(n=6)$.

\begin{tabular}{|l|l|l|l|l|l|l|}
\hline \multicolumn{7}{|c|}{ Attraction } \\
\hline & Sum of squares & df & Mean squares & F & P \\
\hline Between groups & 128.5797101 & 3 & 42.85990338 & 110.9251208 & $.0000^{* * *}$ \\
\hline Within the group & 1.333333333 & 19 & 0.0701754386 & & \\
\hline Total & 129.9130434 & 22 & & & \\
\hline \multicolumn{7}{|c|}{ Sniffing } \\
\hline & Sum of squares & df & Mean squares & F & P \\
\hline Between groups & 132.350724 & 3 & 44.11690821 & 292.4027637 & $.0000^{* * *}$ \\
\hline Within the group & 2.86666666 & 19 & 0.150877193 & & \\
\hline Total & 135.2173913 & 22 & & & \\
\hline \multicolumn{5}{|c|}{ Salivation } & & \\
\hline & Sum of squares & df & Mean squares & F & \\
\hline Between groups & 112.884058 & 3 & 37.62801932 & 3066.3995859 & $.0000^{* * *}$ \\
\hline Within the group & 2.333333333 & 19 & 0.1228070176 & & \\
\hline Total & 115.2173913 & 22 & & & \\
\hline \multicolumn{5}{|c|}{ Urination } & & \\
\hline Between groups & 102.7724638 & 3 & 34.25748792 & 131.052135 & $.0000^{* * *}$ \\
\hline Within the group & 4.966666667 & 19 & 0.2614034088 & & \\
\hline Total & 107.7391305 & 22 & & & \\
\hline
\end{tabular}

Table 2: Analysis of variance (ANOVA) with post hoc comparison (oneway), Homogeneous subsets (Attraction), Homogeneous subsets (Sniffing), Homogeneous subsets (Salivation), Homogeneous subsets (Urination) in different stages of Bovine (Bos taurus) urine.

\begin{tabular}{|c|c|c|c|c|c|}
\hline \multicolumn{6}{|c|}{ Tongue Manipulation } \\
\hline & Sum of squares & df & Mean squares & $\mathrm{F}$ & $P$ \\
\hline Between groups & 101.5 & 3 & 33.83333333 & 225.555555 & $.0000^{* * *}$ \\
\hline Within the group & 3 & 19 & 0.15 & & \\
\hline Total & 104.5 & 22 & & & \\
\hline \multicolumn{6}{|c|}{ Flehmen } \\
\hline & Sum of squares & df & Mean squares & $\mathrm{F}$ & $P$ \\
\hline Between groups & 104.3362319 & 3 & 34.77874396 & 260.8405797 & $.0000^{\star \star *}$ \\
\hline Within the group & 2.5333333 & 19 & 0.13333333334 & & \\
\hline Total & 106.8695652 & 22 & & & \\
\hline \multicolumn{6}{|c|}{ Vocalization } \\
\hline & Sum of squares & df & Mean squares & $\mathrm{F}$ & $P$ \\
\hline Between groups & 961.6666667 & 3 & 32.055555556 & 174.8484848 & $.0000^{* * *}$ \\
\hline Within the group & 3.66666667 & 20 & 0.1833333333 & & \\
\hline Total & 990.83333333 & 23 & & & \\
\hline \multicolumn{6}{|c|}{ Penis Protrusion } \\
\hline & Sum of squares & df & Mean squares & $\mathrm{F}$ & $\mathrm{P}$ \\
\hline Between groups & 64.45942029 & 3 & 21.48647343 & 121.2602956 & $.0000^{* * *}$ \\
\hline Within the group & 3.66666667 & 19 & 0.1771929825 & & \\
\hline Total & 67.82608696 & 22 & & & \\
\hline
\end{tabular}

Table 3: Analysis of variance (ANOVA) with post hoc comparison (one-way), Homogeneous subsets (Tongue Manipulation), Homogeneous subsets (Flehmen), Homogeneous subsets (Vocalization), Homogeneous subsets (Penis Protrusion) in different stages of Bovine (Bos taurus) urine.

\section{Statistical Analyses}

The data were compiled using SPSS version-10.0 (SPSS-X) statistical software and subjected to analysis of variance (ANOVA)

with post hoc comparison (one-way) using Duncan's Multiple Range Test (DMRT).

\section{Results}

The behavioural activities of bulls were observed for a period of 15 minutes and the responses were scored as neutral (no response) and aversive (positive response). During the assay the bull performed a sequence of behaviours like attraction, salivation, urination, tongue manipulation, flehmen and vocalization (Table 1) towards estrus urine, 1-iodoundecane (Figure 1) and to some extent with di-n-propyl phthalate. In continuation with the previous behaviours, the bull was also stimulated to show some other reproductive behaviour like penis protrusion (Table 1) towards cow. Totally, all the behavioural activities were observed and recorded towards estrus urine and estrus-specific synthetic compounds (i.e. 1-iodoundecane) but it was totally absent in control group.

The statistical analyses showed that the compound 1-iodoundecane was significantly activated the male behaviours when compared to estrus urine, di-n-propyl phthalate, and control. The present results showed that the male behaviours were higher towards 1-iodoundecane (estrus specific compound) when compared to other three samples, but at the same time estrus urine was also attracted the male and elucidated various types of behaviours similar to 1-iodoundecane. In contrast control and di-n-propyl phthalate did not activate the male to show various reproductive behaviours as compared to estrus urine and 1-iodoundecane. The various behaviours showed by male towards 1 -iodoundecane was significantly $(\mathrm{P}<0.001)$ higher than that of other samples (Tables 2 and 3).

\section{Discussion}

Among the volatile compounds identified in estrus urine, the behavioural study confirmed that the compound 1-iodoundecane is highly effective in stimulating the bulls for several sexual behavioral responses. By contrast, the compound di-n-propyl phthalate failed to demonstrate such positive responses. The reasons may be because of phthalate/esters derived from laboratory contamination or from plasticizers present in plastic containers in which the urine is frequently collected [16]. It should be noted that the identification of these high boiling compounds are based solely on the software matching algorithm and hence must be considered tentative. It is also noticed that after inhaling the urine, bull frequently lick the genital region and exhibited sexual reproductive behaviours. The bulls revealed a high frequency of flehmen response when exposed to 1-iodoundecane when compared to control and estrus urine. Likewise, the chemosensory responses and pre-mating behaviours of the adult male to the female urinary cues have been well documented [17]. It is reported that mice in the various phases of estrous cycle showed maximum olfactory sensitivity as compared to other phase's indicating the role of ovarian estrogen to olfactory sensitivity in mammals [18].

The behavioural activities exhibited by the bull in response to an 
Citation: Archunan G, Ramesh Kumar K (2012) 1-lodoundecane, an Estrus Indicating Urinary Chemo signal in Bovine (Bos Taurus). J Vet Sci

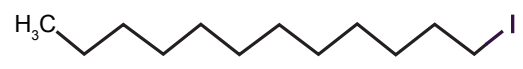

Figure 1: Structure of 1-lodoundecane.

estrous compound (i.e. 1-iodoundecane) show similarities to that seen in the bull in response to natural estrus urine. The present results coincide with the reports that the bulls frequently mount the cows that are in estrus stage [19]. Nevertheless, it is not known whether there are some substances/compounds produced from other sources, which may act together with 1-iodoundecane of urinary source for exhibiting the mating performance. The present finding is in agreement with the earlier reports on identification of estrus-specific urinary Chemosignals in mouse [20] and buffalo [21]; their role as sex-pheromones has been confirmed by bioactivity. Based on various behaviour activities exhibited by bulls suggest that the 1-iodoundecane may be considered as a reliable indicator for estrus, probably a strong stimulator for sexual activities in bull.

\section{Acknowledgements}

We are thankful to Dr. Chellam Balasundaram, Emeritus Professor, Dept. of Animal Science, Bharathidasan University, Tiruchirappalli-24, for critical reading of the manuscript. The work was partially supported by funds from CSIR, DST, DBT and UGC-SAP Govt. of India. KRK acknowledges CSIR, New Delhi, for the award of Research Associateship.

\section{References}

1. Bossert WH, Wilson EO (1963) The analysis of olfactory communication among animals. J Theoret Biol 5: 443-469.

2. Achiraman S, Archunan G (2005) 3-Ethyl-2,7-dimethyl octane, a testosterone dependent unique urinary sex pheromone in male mouse (Mus musculus). Anim Reprod Sci 87: 151-161.

3. Prakash I, Kumari (1979) Occurrence of the ventral marking gland in Indian desert rodents. Saugtl. Mittei 27: 315

4. Brahmachary RL, Dutta J, Poddar-Sarkar M (1991) The marking fluid of tiger. Mammalia 55:150.

5. Rekwot PI, Ogwu D, Oyedipe EO, Sekoni VO (2001) The role of pheromones and biostimulation in animal reproduction. Anim Reprod Sci 65: 157-170.

6. Archunan G (2009) Vertebrate pheromones and their Biological Importance. J Exp Zool 12: 227-239.
7. Ramesh Kumar K, Archunan G, Jeyaraman R, Narasimhan S (2000) Chemical Characterization of Bovine urine with special reference to oestrous. Vet Res Comun 24: 445-454.

8. Mucignat-Caretta C, Colivicchi MA, Fattori M, Ballini C, Bianchi L, et al. (2006) Species-specific chemosignals evoke delayed excitation of the vomeronasa amygdala in freely-moving female rats. J Neurochem 99: 881-891.

9. Schaal B, Coureaud G, Langlois D, Ginies C, Semon E, et al. (2003) Chemica and behavioural characterization of the rabbit mammary pheromone. Nature 424: 68-72.

10. Greenwood DR, Comeskey D, Hunt MB, Rasmussen LE (2005) Chemica communication: Chirality in elephant pheromones. Nature 438:1097-1098.

11. Sankar R, Archunan G (2004) Flehmen response in bull: role of vaginal mucus and other body fluids of bovine with special reference to estrus. Behav Processes 67: 81-86.

12. Sankar R, Archunan G (2008) Identification of putative pheromones in bovine (Bos taurus) faeces in relation to estrus detection. Anim Reprod Sci 103: 149 153.

13. Kiddy CA, Mitchell DS, Hawk HW (1984) Estrus related odours in body fluids of dairy cows. J Dairy Sci 67: 388-391.

14. Klemm WR, Rivard GF, Clement BA (1994) Blood acetaladehyde fluctuates markedly during bovine estrous cycle. Anim Reprod Sci 35: 9-26.

15. Kumar RK, Archunan G, Jeyaraman R, Narasimhan S (2000) Chemical characterization of bovine urine with special reference to estrus. Vet Res Comm 24: 445 .

16. Mattina MJI, Pignatello JJ, Swihart RK (1991) Identification of volatile components of bobcat (Lyx rufus) urine. J Chem Ecol 17: 451-462.

17. Klemm WR, Hawkins GN, De Los Santos E (1987) Identification of compounds in bovine cervico-vaginal mucus extracts that evoke male sexual behaviour. Chem Senses 12: 77-87.

18. Ramesh Kumar K, Archunan G (1999) Influence of the stage of the cycle on olfactory sensitivity in laboratory mice. Indian J Exp Biol 37: 317-318.

19. Reinhardt $\vee$ (1983) Flehmen, mounting and copulation among members of a semi-wild cattle herd. Anim Behav 31: 641-650.

20. Achiraman S, Archunan G, Ponmanickam P, Rameshkumar K, Kannan S, et al. (2006) 1-iodo 2 methylundecane, a putative estrus specific urinary chemosignal of female mice (Mus musculus). Theriogenology 66: 1913-1920.

21. Rajanarayanan S, Archunan G (2011) Identification of urinary sex pheromones in female buffaloes and their influence on bull reproductive behaviour. Res Vet Sci 91: 301-305 